\title{
The association of obstructive sleep apnea and renal outcomes - a systematic review and meta-analysis
}

\author{
Der-Wei Hwu' ${ }^{1,3}$, Kun-Der Lin ${ }^{2,4}$, Kun-Chen Lin ${ }^{1}$, Yau-Jiunn Lee ${ }^{1}$ and Yu-Hung Chang ${ }^{1 *}$ (D)
}

\begin{abstract}
Background: The aim of this systematic review and meta-analysis was to summarize the association of obstructive sleep apnea (OSA) with renal outcome.

Methods: Our study followed the PRISMA guidelines. Two independent reviewers searched for relevant articles in the databases of Pubmed, the Web of Science and CENTRAL, and conducted study selection and quality assessment. A random-effect model was used to estimate the effects.

Results: A total of 1240 articles were initially identified (Pubmed $=568$, Web of Science $=640$, CENTRAL $=32$ ). After removal of duplicate articles $(n=415)$ and irrelevant articles $(n=788), 37$ were selected for full-text review, and 18 were finally included in the analysis. Overall, patients diagnosed with OSA were found to have a higher odds ratio (OR) of a poorer renal outcome, with a pooled OR of 1.77 (95\% C.I.: 1.37-2.29). The significant association between OSA and a poorer renal outcome was not affected by the medical condition of diabetes mellitus (DM). In addition, we found that OSA was consistently associated with higher albuminuria/proteinuria and a lower estimated glomerular filtration rate (eGFR), with a pooled OR of 1.84 (95\% C.I.: 1.24-2.73) and 1.60 (95\% C.I.: 1.19-2.16), respectively. A greater OSA severity was also found to be related to a higher OR, with a mild group OR of 1.45 (95\% C.I.: 1.19-1.77) and a moderate and severe group OR of 2.39 (95\% C.I.: 1.96-2.90).
\end{abstract}

Conclusions: Our study demonstrated that OSA is significantly associated with poorer renal function.

Keywords: Obstructive sleep apnea, Chronic kidney disease, Diabetes, Proteinuria, Albuminuria

\section{Background}

According to data from the National Health and Nutrition Examination Survey, the latest report from the United States Renal Data System indicated that chronic kidney disease (CKD) is more common than diabetes mellitus (DM) in the United States, an estimated 13.6\% of adults having CKD as compared with $12.3 \%$ with DM [1]. Thus, CKD has become a serious public health issue, as it is not only debilitating to individuals, leading to severe complications, but is also a great burden on society, with a large associated cost [2]. Therefore, identifying and disrupting factors that contribute to CKD is not only

\footnotetext{
* Correspondence: yuhungchang@so-net.net.tw

${ }^{1}$ Department of Internal Medicine, Lee's Endocrinology Clinic, \# 130 Min-Tzu Rd, Pingtung 90000, Taiwan

Full list of author information is available at the end of the article
}

beneficial to the health of individuals, but can also reduce the cost of treating the disease and its complications.

Obstructive sleep apnea (OSA) could be a potential risk factor for CKD. In the late 1980s, Sklar et al. initially found that OSA could be significantly associated with high-grade proteinuria [3]; they then confirmed these results in a larger cohort [4]. Subsequently, Canales et al. [5] further established that the degree of microalbuminuria is correlated with the severity of OSA. Moreover, Iseki et al. [6] reported that a Japanese population diagnosed with OSA had a higher chance of decreased renal function, as predicted from the estimated glomerular filtration rate (eGFR). Despite these reports suggesting a relationship between OSA and the development of CKD, other conflicting reports have presented evidence against the existence of a connection of OSA with proteinuria [7], albuminuria [8] and the eGFR [5,9]. Thus, the 
associations of OSA with diverse renal outcomes should be clarified.

Recently, Leong et al. [10] conducted a meta-analysis that focused on patients with DM, and presented moderate evidence to show that OSA is associated with CKD. However, it should be noted that patients with DM are prone to suffering from nephropathy $[2,11]$, and the results may not be able to be generalized to other populations. Furthermore, previous studies $[10,12]$ did not elucidate a relationship between the severity of OSA and the degree of renal function change, which may be worthy of discussion. In order to clarify the uncertainties mentioned above, this meta-analysis study aimed to provide a more comprehensive overview of the relationship between OSA and renal function.

\section{Methods}

Our study followed the PRISMA (Preferred Reporting Items for Systematic Reviews and Meta-Analyses) guidelines [13] during all stages, including design, execution and reporting, when feasible. The present study was registered in the PROPERO database (CRD42015023791).

\section{Literature search}

A systematic literature search was completed at the end of March, 2017. Electronic databases including Pubmed, the Web of Science and the Cochrane Central Register of Controlled Trials (CENTRAL) were searched by two independent investigators (Der-Wei Hwu and Kun-Der Lin). We used a combination of free key words, including "obstructive sleep apnea", "sleep-disordered breathing", "chronic kidney disease", "albuminuria", "proteinuria", "renal function" and "nephropathy", including their MeSH terms, to find relevant articles (see Additional file 1). We also examined published reviews to identify studies that were potentially eligible for inclusion.

\section{Study selection}

We included studies whose participants were aged over 18 years. Articles were excluded based on the following criteria: (1) expert review articles, letters and meeting abstracts; (2) non-English articles; (3) articles that discussed OSA based on a CKD population, for the reason that our aim was to examine renal outcomes in the OSA population. To resolve discrepancies, a consensus was reached with other specialists (Kun-Chen Lin and YauJiunn Lee) who were not involved in the initial search procedure. Study quality was assessed using the Newcastle-Ottawa scale [14].

\section{Definition of OSA}

OSA was defined according to one of the following diagnostic criteria: 1. Apnea-Hypopnea Index (AHI) (as per the American Academy of Sleep Medicine guidance); 2.
Oxygen Desaturation Index (ODI); 3. Respiratory Disturbance Index (RDI). Either polysomnography (PSG) or a pulse oximeter was used to make the diagnosis. The diagnostic criteria used in each study are shown in Table 1.

\section{Renal outcomes}

We included studies that reported renal outcomes according to the status of albuminuria/proteinuria or the eGFR. Albuminuria/proteinuria was defined by the urinary albumin/protein to creatinine ratio. As there are various methods for calculating the eGFR (e.g., MDRD, CKD-EPI), we included eligible studies as long as their methods were described clearly.

\section{Data synthesis and analysis}

Data were extracted using a standardized data extraction form. General information regarding the study (e.g., author, publication year, and study design) and the characteristics of the study population (e.g., age, body mass index, and percentages of subjects with DM, hypertension and CKD) were extracted. For studies that examined more than one of our populations of interest (e.g., DM and non-DM; mild, moderate and severe OSA) or renal outcomes (albuminuria/ proteinuria and eGFR) by subgroup analysis, each result was treated as an independent study in our analysis. For longitudinal studies, we only extracted the before-after changes in renal outcomes, which are more convincing than cross-sectional data. For studies that lacked important numeric values, we attempted to contact the original authors to obtain the missing data.

We used a random-effect model to conduct our metaanalysis owing to the significant heterogeneities among the included studies (e.g., variations in study design, study population, measurements of OSA and renal outcomes). If the data were presented as medians instead of averages, and ranges or quartiles instead of standard deviations, they were first converted into averages and standard deviations using the equations provided by Hozo et al. [15]. In each meta-analysis, if multiple data entries were presented in one study, we pooled these data into a single data entry in the analysis via the equations provided by Borenstein et al. [16]. Owing to the fact that our preliminary data included binary outcomes and continuous variables, we transformed the continuous variables into ORs (see Additional file 2) in order to make our results less complicated and easier to understand.

We discussed the overall relationship of OSA with renal function, and presented subgroup results by study design, verifying the results of Leong et al. [10] via subgroup analysis of diabetes status. For studies that included a population of mixed diabetes status, we considered those with a DM population $<40 \%$ as non-DM studies. The reason for choosing $40 \%$ as the cut-off point was that clinical information obtained from a subgroup consisting of less 


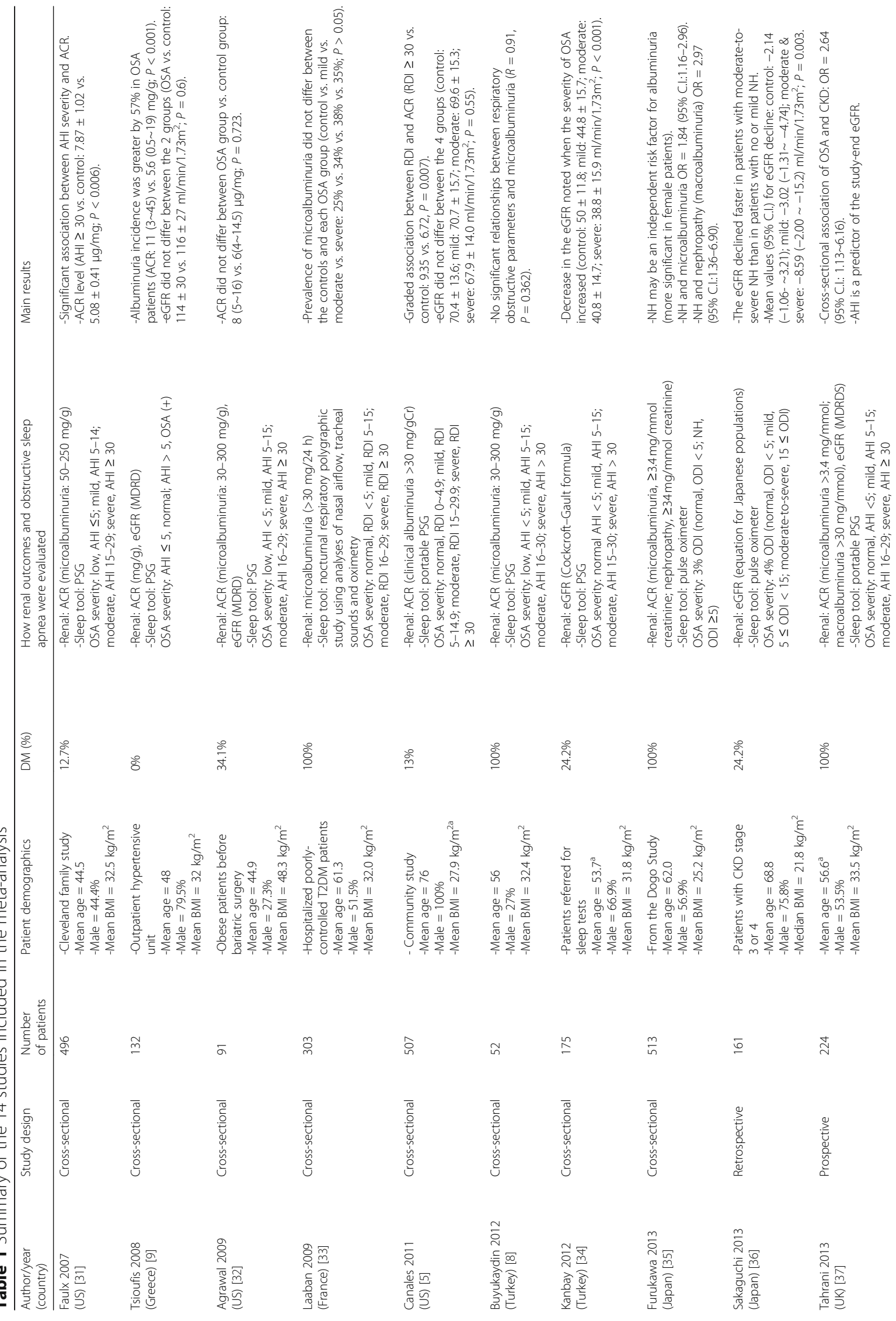




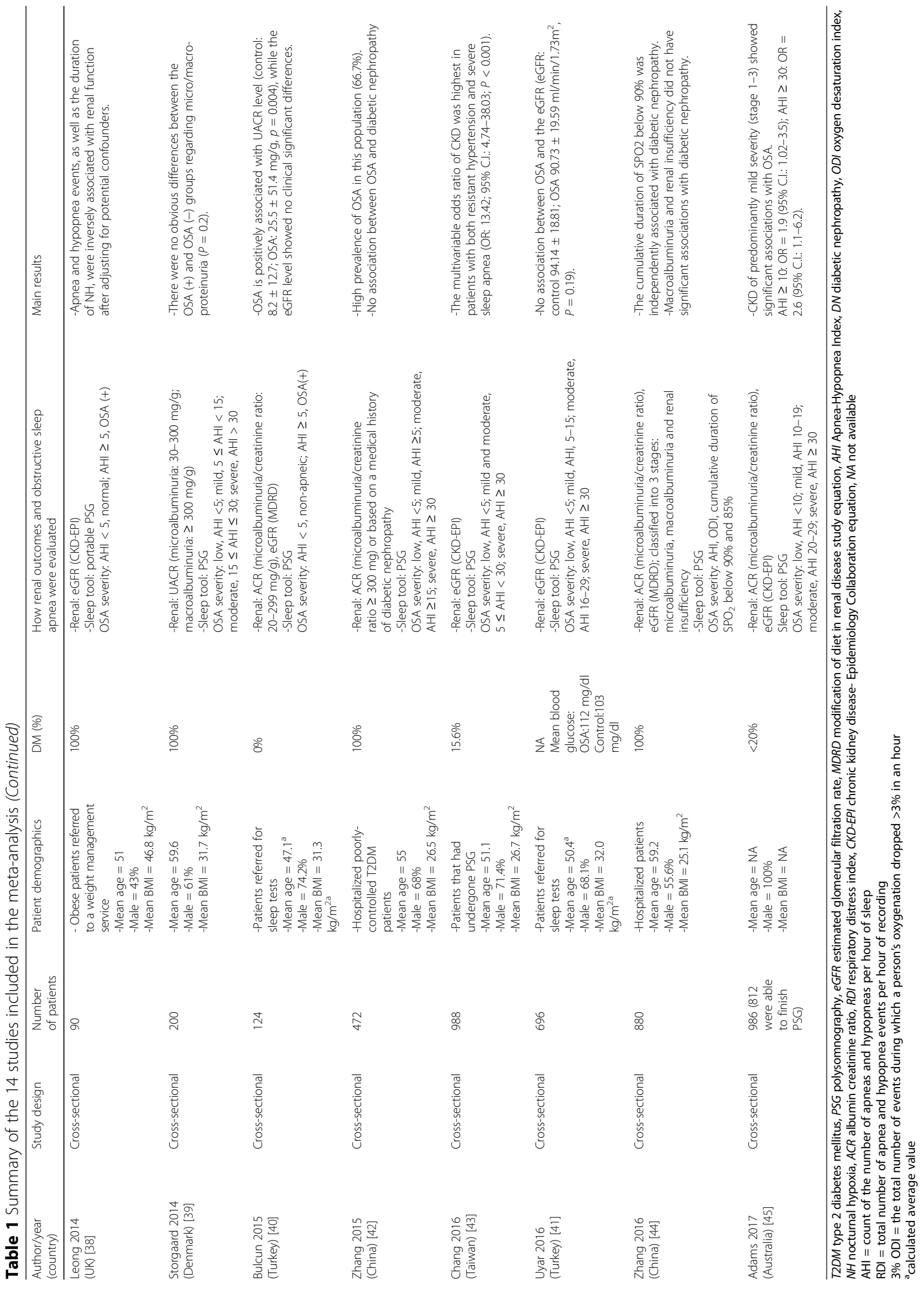


than $40 \%$ of the study population may lack clinical significance, as explained by Wittes et al. [17]. We also performed subgroup analysis according to the eGFR, proteinuria/albuminuria and OSA severity in order to clarify the association between OSA and renal function. Odds ratios (ORs) were used to present the relationship between OSA and CKD. Publication bias was assessed by Egger's test. All of the analyses were performed using Comprehensive Meta-Analysis 2.0 software (Biostat, Englewood, NJ, https://www.meta-analysis.com/). We considered a $P$-value of less than 0.05 to indicate statistical significance.

\section{Results}

A flow diagram of the search for relevant trials is presented in Fig. 1. In total, 1240 studies were initially identified (Pubmed $=568$, Web of Science $=640$, CENTRAL $=32$ ). After removal of duplicate articles $(n=415)$ and irrelevant articles $(n=788), 37$ articles were selected for full-text review. A further 19 articles were excluded following detailed review, of which 3 were review articles, which we reviewed to find potential relevant articles [10, 12, 18]. The remaining 16 were excluded for the following reasons: 1 focused on central apnea [19], 6 did not have a clear definition of nephropathy [20-25], 3 may have contained biased data (e.g., 1 related to creatinine clearance, i.e., over $200 \mathrm{ml} / \mathrm{min}$ [26], 2 had fewer than 10 subgroup participants [27, 28]), 3 had missing data $[6,7,29]$, and 1 focused

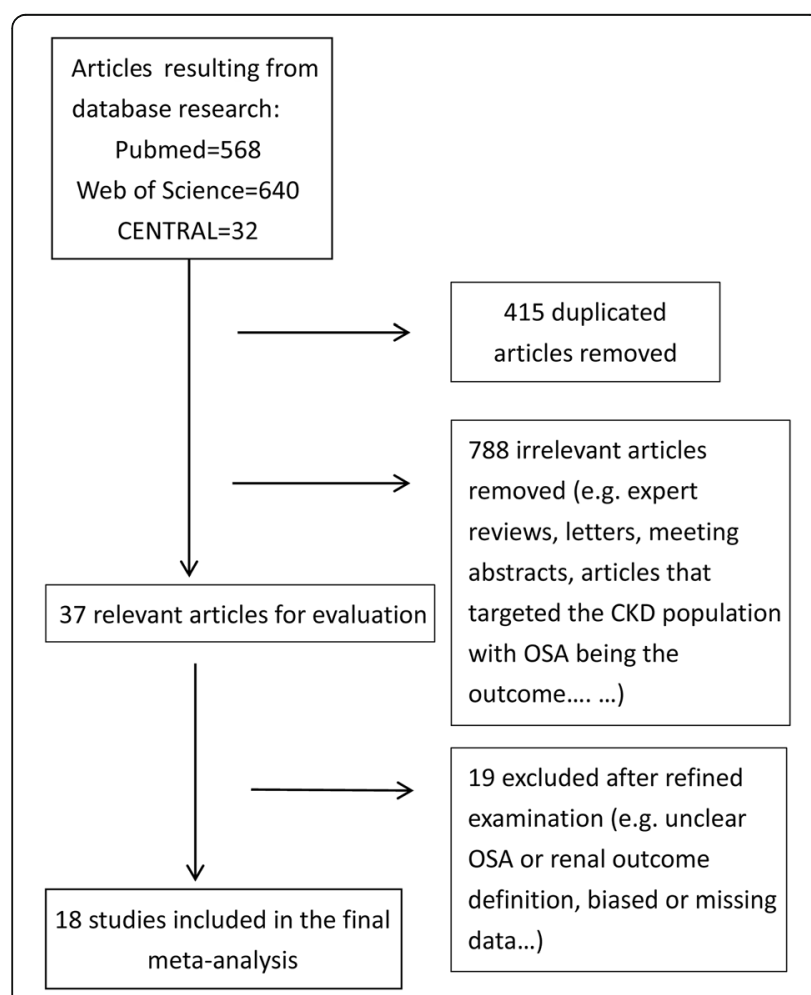

Fig. 1 Flow chart of article extraction for meta-analysis only on the OSA population without a control group [30]. Finally, 18 studies [5, 8, 9, 31-45] that included 7090 patients were incorporated in our meta-analysis.

\section{Study characteristics}

A summary of the 18 studies is presented in Table 1. Two of the 18 studies were longitudinal $[36,37]$, the rest being cross-sectional $[5,8,9,31-35,38-45]$. Three of the studies were performed in the US [5, 31, 32], 2 in Japan [35, 36], 1 in Taiwan [43], 2 in China [42, 44], 1 in Australia [45], and the rest in Europe [8, 9, 33, 34, 37-41]. Fourteen studies used the AHI to diagnose OSA, while OSA was defined using the ODI $[35,36]$ or RDI $[5,33]$ in the remaining studies.

\section{Meta-analysis results}

The overall association of OSA with renal function is shown in Fig. 2. We identified a significant relationship between OSA and poorer renal function, with a pooled OR of 1.77 (95\% C.I.: $1.37-2.29 ; P<0.001$ ); this association did not change significantly with different study designs $(\mathrm{OR}=1.71,95 \%$ C.I.: $1.31-2.23 ; P<0.001$ for cross-sectional studies; OR $=2.74$, 95\% C.I.: 1.08-6.96; $P=0.03$ for longitudinal studies). By subgroup analysis (Fig. 3), we not only confirmed the results of the study by Leong et al. [10], which reported that OSA is significantly associated with poorer renal function in patients with DM (OR $=1.70$; 95\% C.I.: $1.04-2.77 ; P=0.03)$, but also expanded this association to patients without DM $(\mathrm{OR}=1.83$; 95\% C.I.: $1.58-2.12 ; P<0.001)$. OSA was associated with adverse renal outcomes, whether represented by albuminuria/proteinuria $(\mathrm{OR}=1.84 ; 95 \%$ C.I.: 1.24-2.72; $P<0.001$ ) or by the eGFR (OR $=1.60 ; 95 \%$ C.I.: 1.19-2.16; $P<0.001$ ) (Fig. 4). In addition, we demonstrated for the first time that impaired renal outcome could occur even in patients with mild OSA $(\mathrm{OR}=1.45$; 95\% C.I.: $1.19-1.77 ; P<0.001$ ), and the numeric value of the OR was higher in patients with moderate or severe OSA, which may be taken as indirect evidence showing that OSA acts as a contributing factor to a poorer renal outcome $(\mathrm{OR}=2.39 ; 95 \%$ C.I.: $1.96-2.90 ; P<0.001)$ (Fig. 5).

With regards to all analyses, no publication bias was found by Egger's test. No studies in individual populations dramatically influenced the overall results according to the outcomes of the remove-one-study sensitivity test in the meta-analysis.

\section{Quality assessment}

Table 2 summarizes the results in terms of study quality. The overall quality scores were averaged, with 8 studies rated moderate, 6 studies rated strong, and 4 rated weak. The blinding component and study design component had the lowest ratings. 


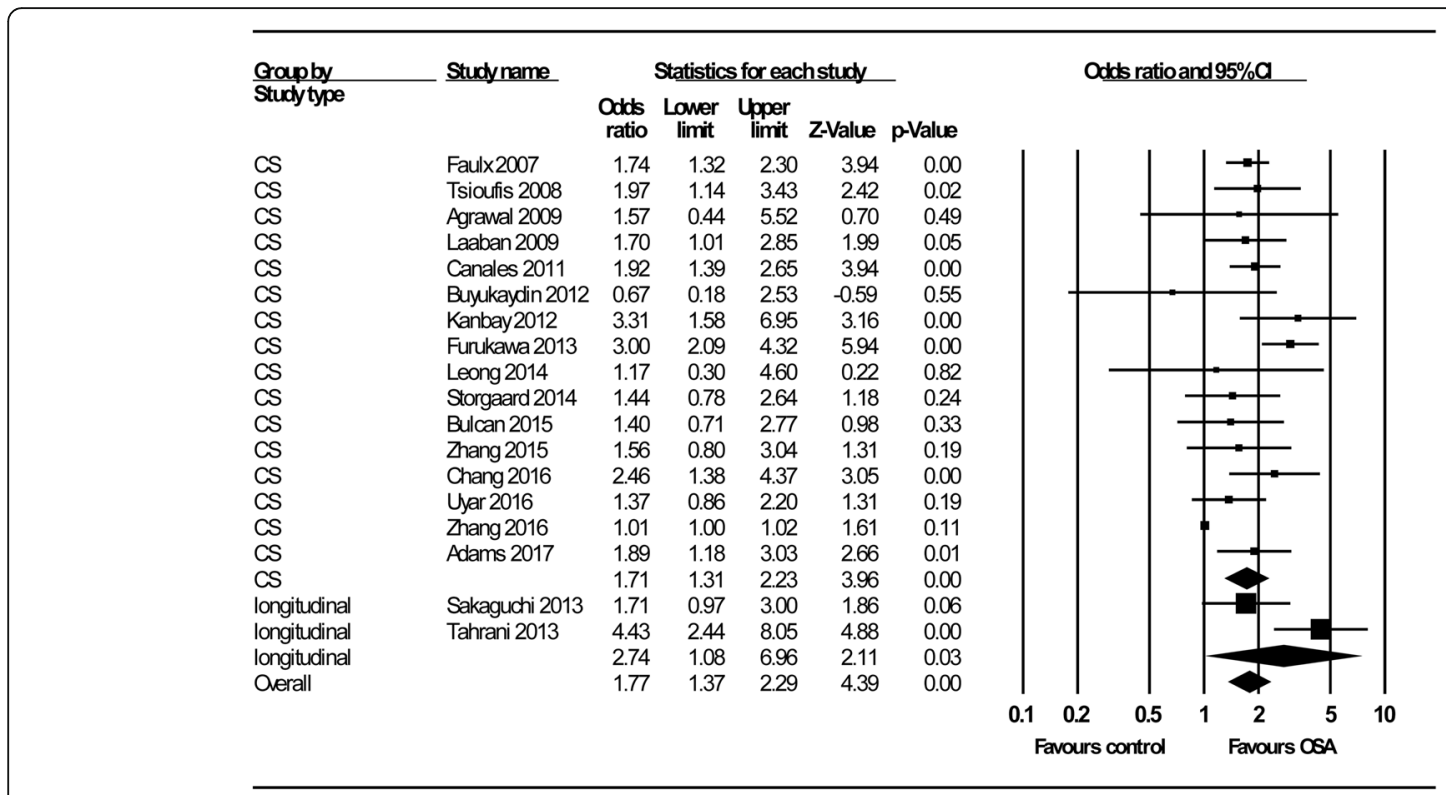

Fig. 2 Meta-analysis results regarding the impact of OSA on CKD

\section{Discussion}

Our results indicated that OSA is not only significantly associated with poorer renal function in patients with DM, but also in patients without DM. In addition, we consolidated the significance of OSA in poorer renal function by reporting on different study designs, renal outcomes (eGFR or albuminuria/proteinuria) and OSA severities.

A recent meta-analysis by Leong [10] demonstrated that OSA is associated with poorer renal function in the diabetic population. However, the nature of diabetic patients leaves them more prone to suffering from nephropathy $[2,11]$, and therefore it could be suspected that this association may not apply to populations without DM. However, in our analysis, we not only confirmed that OSA is significantly associated with poorer renal function in diabetic patients, but also found that this relationship may also apply to non-diabetic patients. Thus, healthcare providers should be aware of the symptoms of OSA in clinical practice.

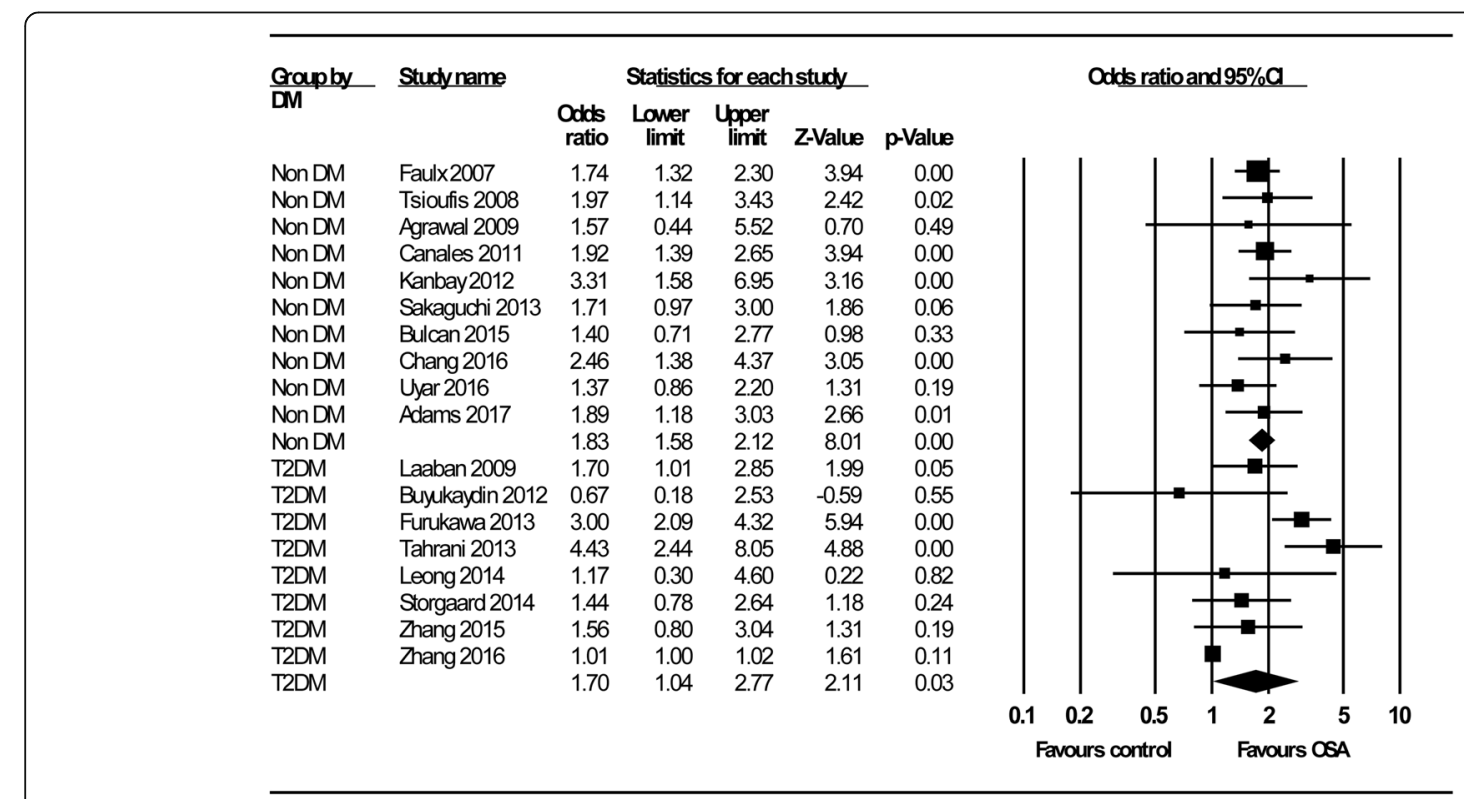

Fig. 3 Subgroup analysis by diabetes status 


\begin{tabular}{|c|c|c|c|c|c|c|}
\hline \multirow{2}{*}{$\frac{\text { Group by }}{\text { CKD }}$} & \multirow[t]{2}{*}{ Study name } & \multicolumn{5}{|c|}{ Statistics for each study } \\
\hline & & $\begin{array}{l}\text { Odds } \\
\text { ratio }\end{array}$ & $\begin{array}{c}\text { Lower } \\
\text { limit }\end{array}$ & $\begin{array}{c}\text { Upper } \\
\text { limit }\end{array}$ & Z-Value & p-Value \\
\hline albumin/proteinuria & Faux 2007 & 1.74 & 1.26 & 240 & 3.37 & 0.00 \\
\hline albumin/protennuia & Tsiaufis 2008 & 3.43 & 1.81 & 6.49 & 3.79 & 0.00 \\
\hline albumin/prodenuia & Agrand 2009 & 1.57 & 0.44 & 5.52 & 0.70 & 0.49 \\
\hline abumin/protenuria & Ladban 2009 & 1.70 & 1.01 & 285 & 1.99 & 0.05 \\
\hline albumin/protenuria & Canles 2011 & 3.41 & 233 & 4.98 & 6.34 & 0.00 \\
\hline abumin/protenuia & Buyukaydin 2012 & 0.67 & 0.18 & 253 & -0.59 & 0.55 \\
\hline albumin/protenuria & Funkava 2013 & 3.00 & 200 & 4.32 & 5.94 & 0.00 \\
\hline abumin/protenuria & Storgaard 2014 & 1.44 & 0.78 & 264 & 1.18 & 0.24 \\
\hline abumin/protenuria & Bucan 2015 & 1.97 & 0.90 & 4.34 & 1.69 & 0.09 \\
\hline abumin/prodenuria & Zhang 2015 & 1.56 & 0.80 & 3.04 & 1.31 & 0.19 \\
\hline albumin/protenuria & Zhang 2016 & 1.01 & 0.99 & 1.02 & 0.83 & 0.40 \\
\hline abumin/proteinuria & & 1.84 & 1.24 & 272 & 3.02 & 0.00 \\
\hline eGFR & Faux (eGFR) 2007 & 1.74 & 1.26 & 239 & 3.36 & 0.00 \\
\hline eGFR & Tsiauf is (eGRR) 2008 & 1.14 & 0.61 & 211 & 0.40 & 0.69 \\
\hline eGFR & Canales (eGFR) 2011 & 1.08 & 0.74 & 1.56 & 0.39 & 0.69 \\
\hline eGFR & Kanbey 2012 & 3.31 & 1.58 & 6.95 & 3.16 & 0.00 \\
\hline eGFR & Skzagurti 2013 & 1.71 & 0.97 & 3.00 & 1.86 & 0.06 \\
\hline eGFR & Tatrani 2013 & 4.43 & 244 & 8.05 & 4.88 & 0.00 \\
\hline eGFR & Leang 2014 & 1.17 & 0.30 & 4.60 & 0.22 & 0.82 \\
\hline eGFR & Buan (eGFR) 2015 & 1.00 & 0.46 & 219 & 0.00 & 1.00 \\
\hline eGFR & Chang 2016 & 246 & 1.38 & 4.37 & 3.05 & 0.00 \\
\hline EGFR & Uyar 2016 & 1.37 & 0.86 & 220 & 1.31 & 0.19 \\
\hline eGFR & Zhang (eGFR) 2016 & 1.02 & 1.00 & 1.04 & 1.60 & 0.11 \\
\hline eGFR & & 1.60 & 1.19 & 216 & 3.13 & 0.00 \\
\hline
\end{tabular}

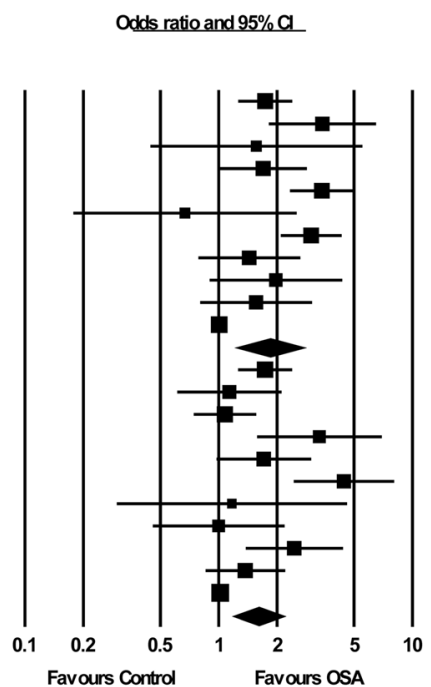

Fig. 4 Subgroup analysis by renal outcomes

Possible mechanisms of the interaction between OSA and renal function change have been proposed. Turek et al. [12] pointed out that a specific feature of OSA is intermittent hypoxia followed by reoxygenation, stimulating the formation of reactive oxygen species, which promote inflammation and systemic endothelial dysfunction. During the hypoxia period, the rise in sympathetic tone and activation of the renin-angiotensin system cause the systematic and intraglomerular pressure to rise [46]. Therefore, it is plausible that the risk of CKD increases in parallel with an increased hypoxia duration and greater frequency, as confirmed in the meta-analysis examining the relationship of OSA severity with renal outcome. Of note, our results showing that there is an increased risk of CKD even in patients with mild OSA may be of particular importance, as there has been disagreement regarding treatment for patients with mild OSA $[47,48]$. Thus, our result may present a different perspective on the clinical management of patients with OSA.

Despite our results suggesting a close relationship between OSA and poorer renal function, and implying that medical therapy that alleviates OSA could slow the development of CKD, clear evidence is still lacking. In a subgroup population with moderate-to-severe OSA, Tahrani et al. [37] demonstrated that participants adherent to continuous positive airway pressure (CPAP) therapy exhibited a slower decline in renal function as compared with CPAP non-adherent patients $(-7.7 \%$ vs. $-10 \%)$. In a

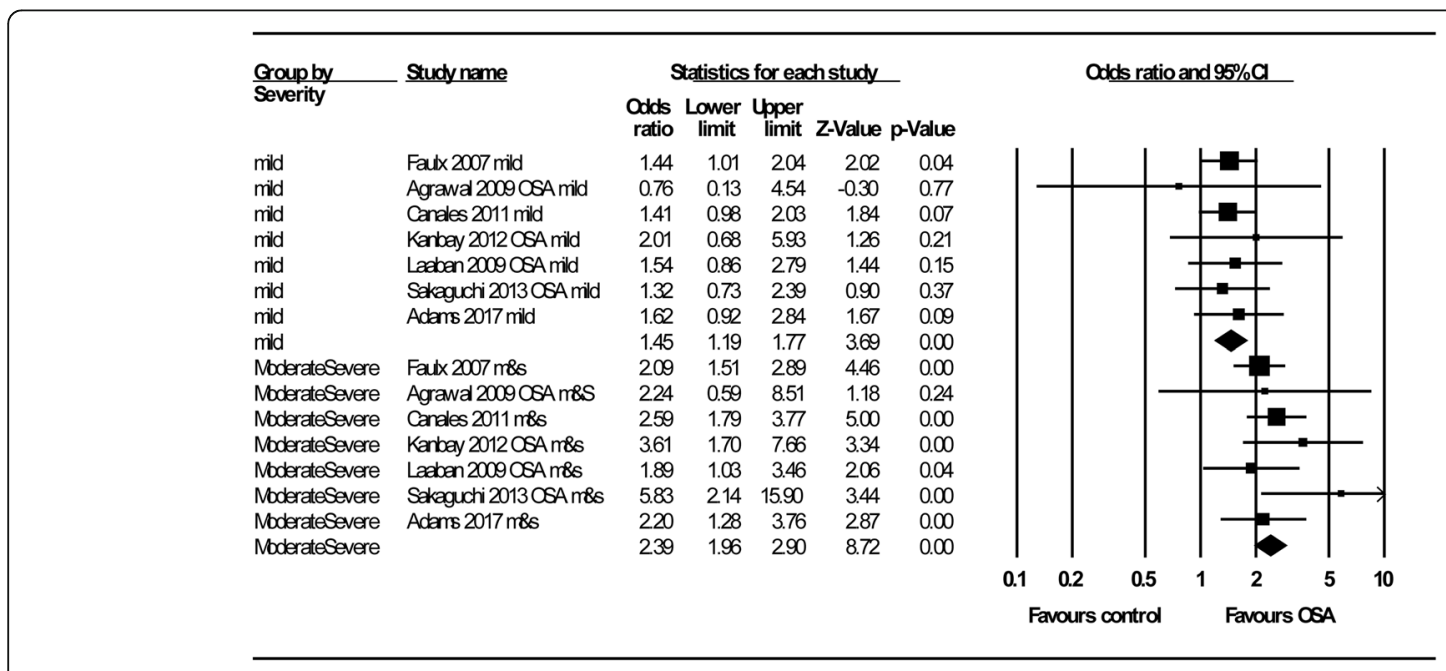

Fig. 5 Subgroup analysis by OSA severity 
Table 2 Newcastle-Ottawa scale for quality assessment

\begin{tabular}{|c|c|c|c|c|c|c|}
\hline Study & Selection bias & Respiratory measurement & Blinding & Study design & Analysis & Overall \\
\hline Faulx 2007 [31] & Moderate & Strong & Weak & Weak & Strong & $\overline{\text { Moderate }}$ \\
\hline Tsioufis 2008 [9] & Strong & Strong & Weak & Weak & Strong & Strong \\
\hline Agrawal 2009 [32] & Moderate & Strong & Strong & Weak & Strong & Strong \\
\hline Laaban 2009 [33] & Moderate & Moderate & Weak & Weak & Moderate & Moderate \\
\hline Canales 2011 [5] & Weak & Moderate & Weak & Weak & Strong & Weak \\
\hline Buyukaydin 2012 [8] & Weak & Strong & Weak & Weak & Weak & Weak \\
\hline Kanbay 2012 [34] & Moderate & Strong & Weak & Weak & Moderate & Weak \\
\hline Furukawa 2013 [35] & Weak & Moderate & Weak & Weak & Strong & Weak \\
\hline Sakaguchi 2013 [36] & Weak & Strong & Weak & Moderate & Moderate & Moderate \\
\hline Tahrani 2013 [37] & Weak & Strong & Weak & Strong & Strong & Strong \\
\hline Leong 2014 [38] & Strong & Strong & Strong & Moderate & Strong & Strong \\
\hline Storgaard 2014 [39] & Strong & Strong & Weak & Weak & Weak & Moderate \\
\hline Bulcun 2015 [40] & Strong & Strong & Weak & Moderate & Strong & Strong \\
\hline Zhang 2015 [42] & Moderate & Moderate & Weak & Weak & Moderate & Moderate \\
\hline Chang 2016 [43] & Strong & Strong & Weak & Weak & Strong & Strong \\
\hline Uyar 2016 [41] & Strong & Strong & Weak & Weak & Moderate & Moderate \\
\hline Zhang 2016 [44] & Strong & Moderate & Weak & Moderate & Strong & Moderate \\
\hline Adams 2017 [45] & Moderate & Strong & Weak & Weak & Strong & Moderate \\
\hline
\end{tabular}

retrospective study, Puckrin et al. [49] reported that participants who underwent CPAP therapy more often had lesser renal function decline and proteinuria. Despite these reports indicating a promising utility of CPAP for renal function protection in OSA patients, the results are limited by the small number of participants $(<50)[37,49]$, a lack of statistical significance [37], and potential confounders in a retrospective study design [49]. In addition, these reports also truthfully reflect the limitations of CPAP in clinical practice, as most patients under OSA management have been found to be non-adherent $(>60 \%)$ to CPAP [37, 49]. In the context that none of these reports showed any renal benefit of CPAP in mild OSA patients [37], further investigation may be necessary to ascertain the benefits of OSA management in CKD patients.

One of the purposes of this meta-analysis was to resolve discrepancies between some studies concerning the association between OSA and CKD. In a report based on 507 community-dwelling elderly men, Canales et al. showed that the severity of albuminuria increased with increasing severity of OSA, but the eGFR did not decrease with increasing severity of OSA [5]. Likewise, in a study that included 132 patients with untreated hypertension, Tsioufis et al. found that patients with OSA exhibited a higher degree of albuminuria, but there was no difference in renal function as estimated from the eGFR [9]. These reports may confuse the association between OSA and CKD. However, it should be noted again that albuminuria is an early indicator of renal damage, and a longer duration may be needed in order to observe a change in the eGFR. In addition, these results may be hampered by the limitations of the crosssectional design, in terms of not being able to provide a clear chain of consequence between OSA and CKD. In contrast to these two studies, in a prospective cohort study based on 224 type 2 DM (T2DM) patients, Tahrani et al. [37] not only showed that in patients with OSA, the prevalence of diabetic nephropathy at baseline was significantly higher, but also clearly indicated that T2DM patients with OSA exhibited a greater eGFR decline at the end of the 2.5-year follow-up period. Taking these results together with the results of our meta-analysis, we concluded that OSA is significantly associated with poorer renal function, whether defined by albuminuria/ proteinuria or the eGFR.

There were several limitations in our study. First, among the 18 eligible studies, only 2 cohort studies discussed the impact of OSA on renal function change $[36,37]$. Of note, only one study was of a prospective design [37], the other being retrospective in nature [36]. Owing to study results potentially being biased by the nature of the study design, our results should be interpreted with caution. Second, it has been reported that there is an approximate $40 \%$ variation in the measurement of albuminuria [50], and significant inconsistency exists among various eGFR formulas [51]. Thus, our results may be biased by the renal function measurements obtained in these studies. Third, to maximize the information available, we artificially transformed the renal outcomes reported in some studies into odds ratios, which 
may have overinflated the results. Also, in most of included studies, unadjusted analyses were performed, and residual confounders remained. Thus, our results should be interpreted carefully. Fourth, our results may also be biased by the different diagnostic tools used to define OSA; they also may not apply to young adults, as most of the included study populations were aged over 50 . Despite these limitations, our study is of merit in terms of showing a consistent and clear association between OSA and CKD from different perspectives. In addition, compared with other articles [10], our results were based on more sophisticated evidence in terms of not including potentially biased reports (e.g., including meeting abstracts [52, 53], studies with an unclear renal outcome definition, etc. [21]). Based on the above discussion, our results may provide additional information relevant to clinical practice.

\section{Conclusions}

In conclusion, our results indicated that OSA was significantly related to poorer renal function, suggesting that diagnosis of OSA should not be overlooked in clinical practice. Larger prospective studies may be necessary in order to compare renal outcomes with/without medical intervention to provide more persuasive data regarding the causality between OSA and renal function, particularly in patients with mild OSA.

\section{Additional files}

Additional file 1: Search terms for Pubmed, Web of Science and CENTRAL databases. (DOCX $13 \mathrm{~kb}$ )

Additional file 2: Transforming continuous variables into odds ratios (ORs). (DOCX $22 \mathrm{~kb})$

\section{Abbreviations \\ AHI: Apnea-Hypopnea Index; CENTRAL: Cochrane Central Register of Controlled Trials; CKD: Chronic kidney disease; CPAP: Continuous positive airway pressure; DM: Diabetes mellitus; eGFR: Estimated glomerular filtration rate; ODI: Oxygen Desaturation Index; OR: Odds rations; OSA: Obstructive sleep apnea; PRISMA: Preferred Reporting Items for Systematic Reviews and Meta-Analyses; PSG: Polysomnography; RDI: Respiratory Disturbance Index; T2DM: Type 2 DM}

\section{Acknowledgements}

We thank Dr. Banu Buyukaydin for his kind reply to our email and for providing further information related to his article entitled "The effect of sleep apnea syndrome on the development of diabetic nephropathy in patients with type 2 diabetes".

\section{Funding}

The authors received no funding.

\section{Availability of data and materials}

The datasets generated and analyzed during the current study are available from the corresponding author on reasonable request.

\section{Authors' contributions}

DWH and $K D L$ were responsible for the initial database search. $K C L$ and $Y J L$ reviewed the articles again and resolved discrepancies. DWH and YHC wrote the manuscript and performed the statistical analysis. YJL edited the final draft. All authors read and approved the final manuscript.
Ethical approval and consent to participate

Not applicable

\section{Consent for publication}

Not applicable

Competing interests

The authors declare that they have no competing interests.

\section{Publisher's Note}

Springer Nature remains neutral with regard to jurisdictional claims in published maps and institutional affiliations.

\section{Author details}

${ }^{1}$ Department of Internal Medicine, Lee's Endocrinology Clinic, \# 130 Min-Tzu Rd, Pingtung 90000, Taiwan. ${ }^{2}$ Division of Endocrinology and Metabolism, Department of Internal Medicine, Kaohsiung Medical University Hospital, Kaohsiung Medical University, No. 100, Tzyou 1st Rd, San-Ming District, Kaohsiung, Taiwan. ${ }^{3}$ Graduate institute of Clinical Medicine, Kaohsiung Medical University, Taiwan, No. 100, Shih-Chuan 1st Rd, San-Ming District, Kaohsiung, Taiwan. ${ }^{4}$ Department of Internal Medicine, Kaohsiung Municipal Ta-Tung Hospital, Kaohsiung Medical University, Kaohsiung, Taiwan, No.68, Jhonghua 3rd Rd, Cianjin District, Kaohsiung 80145, Taiwan.

Received: 23 May 2017 Accepted: 29 September 2017

Published online: 16 October 2017

\section{References}

1. Saran R, Li Y, Robinson B, Abbott KC, Agodoa LY, Ayanian J, Bragg-Gresham J, Balkrishnan R, Chen JL, Cope E, et al. US renal data system 2015 annual data report: epidemiology of kidney disease in the United States. Am J Kidney Dis. 2016:67(3 Suppl 1):Svii. S1-305

2. Jha V, Garcia-Garcia G, Iseki K, Li Z, Naicker S, Plattner B, Saran R, Wang AY, Yang CW. Chronic kidney disease: global dimension and perspectives. Lancet. 2013;382(9888):260-72.

3. Sklar AH, Chaudhary BA. Reversible proteinuria in obstructive sleep apnea syndrome. Arch Intern Med. 1988;148(1):87-9.

4. Chaudhary BA, Sklar AH, Chaudhary TK, Kolbeck RC, Speir WA Jr. Sleep apnea, proteinuria, and nephrotic syndrome. Sleep. 1988;11(1):69-74.

5. Canales MT, Paudel ML, Taylor BC, Ishani A, Mehra R, Steffes M, Stone KL, Redline S, Ensrud KE. Osteoporotic fractures in men study G: sleepdisordered breathing and urinary albumin excretion in older men. Sleep Breath. 2011;15(1):137-44.

6. Iseki K, Tohyama K, Matsumoto T, Nakamura H. High prevalence of chronic kidney disease among patients with sleep related breathing disorder (SRBD). Hypertens Res. 2008;31(2):249-55.

7. Mello P, Franger M, Boujaoude Z, Adaimy M, Gelfand E, Kass J, Weisberg LS. Night and day proteinuria in patients with sleep apnea. Am J Kidney Dis. 2004;44(4):636-41.

8. Buyukaydin B, Akkoyunlu ME, Kazancioglu R, Karakose F, Ozcelik HK, Erkoc R, Kart $L$. The effect of sleep apnea syndrome on the development of diabetic nephropathy in patients with type 2 diabetes. Diabetes Res Clin Pract. 2012; 98(1):140-3

9. Tsioufis C, Thomopoulos C, Dimitriadis K, Amfilochiou A, Tsiachris D, Selima M, Petras D, Kallikazaros I, Stefanadis C. Association of obstructive sleep apnea with urinary albumin excretion in essential hypertension: a crosssectional study. Am J Kidney Dis. 2008;52(2):285-93.

10. Leong WB, Jadhakhan F, Taheri S, Thomas GN, Adab P. The association between obstructive sleep apnea on diabetic kidney disease: a systematic review and meta-analysis. Sleep. 2016;39(2):301-8.

11. Wu B, Bell K, Stanford A, Kern DM, Tunceli O, Vupputuri S, Kalsekar I, Willey V. Understanding CKD among patients with T2DM: prevalence, temporal trends, and treatment patterns-NHANES 2007-2012. BMJ Open Diabetes Res Care. 2016;4(1):e000154.

12. Turek NF, Ricardo AC, Lash JP. Sleep disturbances as nontraditional risk factors for development and progression of CKD: review of the evidence. Am J Kidney Dis. 2012;60(5):823-33.

13. Moher D, Liberati A, Tetzlaff J, Altman DG, Group P. Preferred reporting items for systematic reviews and meta-analyses: the PRISMA statement. PLOS Med. 2009;6(7):e1000097. 
14. Stang A. Critical evaluation of the Newcastle-Ottawa scale for the assessment of the quality of nonrandomized studies in meta-analyses. Eur J Epidemiol. 2010;25(9):603-5.

15. Hozo SP, Djulbegovic B, Hozo I. Estimating the mean and variance from the median, range, and the size of a sample. BMC Med Res Methodol. 2005;5:13.

16. Michael Borenstein LVH, Julian P. T. Higgins, Hannah R. Rothstein: introduction to meta-analysis; 2009.

17. Wittes J. On looking at subgroups. Circulation. 2009;119(7):912-5.

18. Leong WB, Jadhakhan F, Taheri S, Chen YF, Adab P, Thomas GN. Effect of obstructive sleep apnoea on diabetic retinopathy and maculopathy: a systematic review and meta-analysis. Diabet Med. 2016;33(2):158-68

19. Fleischmann G, Fillafer G, Matterer H, Skrabal F, Kotanko P. Prevalence of chronic kidney disease in patients with suspected sleep apnoea. Nephrol Dial Transplant. 2010;25(1):181-6.

20. Kosseifi S, Bailey B, Price R, Roy TM, Byrd RP Jr, Peiris AN. The association between obstructive sleep apnea syndrome and microvascular complications in well-controlled diabetic patients. Mil Med. 2010;175(11): 913-6.

21. Schober AK, Neurath MF, Harsch IA. Prevalence of sleep apnoea in diabetic patients. Clin Respir J. 2011;5(3):165-72.

22. Ting $\mathrm{H}$, Liou CM, Shih TS, Wang $\mathrm{CH}$, Chang SY, Chung AH, Lee JF, Wang L, Huang RJ, Lee SD. Obstructive sleep apnea rather than diabetes or obesity associated with proteinuria in late mid-aged male workers: a decision tree analysis. Sleep Breath. 2015;19(4):1167-74.

23. Zhao LP, Kofidis T, Chan SP, Ong TH, Yeo TC, Tan HC, Lee CH. Sleep apnoea and unscheduled re-admission in patients undergoing coronary artery bypass surgery. Atherosclerosis. 2015;242(1):128-34

24. Chu H, Shih CJ, Ou SM, Chou KT, Lo YH, Chen YT. Association of sleep apnoea with chronic kidney disease in a large cohort from Taiwan. Respirology. 2016;21(4):754-60

25. Molnar MZ, Mucsi I, Novak M, Szabo Z, Freire AX, Huch KM, Arah OA, Ma JZ, $\mathrm{Lu} J \mathrm{~L}, \operatorname{Sim} J \mathrm{~J}$, et al. Association of incident obstructive sleep apnoea with outcomes in a large cohort of US veterans. Thorax. 2015;70(9):888-95.

26. Casserly LF, Chow N, Ali S, Gottlieb DJ, Epstein LJ, Kaufman JS. Proteinuria in obstructive sleep apnea. Kidney Int. 2001;60(4):1484-9.

27. Ursavas A, Karadag M, Gullulu M, Demirdogen E, Coskun F, Onart S, Gozu $\mathrm{RO}$. Low-grade urinary albumin excretion in normotensive/non-diabetic obstructive sleep apnea patients. Sleep Breath. 2008:12(3):217-22.

28. Chou YT, Lee PH, Yang CT, Lin CL, Veasey S, Chuang LP, Lin SW, Lin YS, Chen $\mathrm{NH}$. Obstructive sleep apnea: a stand-alone risk factor for chronic kidney disease. Nephrol Dial Transplant. 2011;26(7):2244-50.

29. Ahmed SB, Ronksley PE, Hemmelgarn BR, Tsai WH, Manns BJ, Tonelli M, Klarenbach SW, Chin R, Clement FM, Hanly PJ. Nocturnal hypoxia and loss of kidney function. PLoS One. 2011;6(4):e19029.

30. Chen NH, Chou YT, Lee PH, Lin SW, Chuang LP, Lin YS, Yang CT. Reversibility of albuminuria and continuous positive airway pressure compliance in patients of obstructive sleep apnea syndrome. Medicine (Baltimore). 2016;95(26):e4045.

31. Faulx MD, Storfer-Isser A, Kirchner HL, Jenny NS, Tracy RP, Redline S. Obstructive sleep apnea is associated with increased urinary albumin excretion. Sleep. 2007;30(7):923-9.

32. Agrawal V, Vanhecke TE, Rai B, Franklin BA, Sangal RB, McCullough PA. Albuminuria and renal function in obese adults evaluated for obstructive sleep apnea. Nephron Clinical practice. 2009;113(3):c140-7.

33. Laaban JP, Daenen S, Leger D, Pascal S, Bayon V, Slama G, Elgrably F. Prevalence and predictive factors of sleep apnoea syndrome in type 2 diabetic patients. Diabetes Metab. 2009;35(5):372-7.

34. Kanbay A, Buyukoglan H, Ozdogan N, Kaya E, Oymak FS, Gulmez I, Demir R, Kokturk O, Covic A. Obstructive sleep apnea syndrome is related to the progression of chronic kidney disease. Int Urol Nephrol. 2012;44(2):535-9.

35. Furukawa S, Saito I, Yamamoto S, Miyake T, Ueda T, Niiya T, Torisu M, Kumagi T, Sakai T, Minami H, et al. Nocturnal intermittent hypoxia as an associated risk factor for microalbuminuria in Japanese patients with type 2 diabetes mellitus. Eur J Endocrinol. 2013;169(2):239-46.

36. Sakaguchi Y, Hatta T, Hayashi T, Shoji T, Suzuki A, Tomida K, Okada N, Rakugi H, Isaka Y, Tsubakihara Y. Association of nocturnal hypoxemia with progression of CKD. Clin J Am Soc Nephrol. 2013;8(9):1502-7.

37. Tahrani AA, Ali A, Raymond NT, Begum S, Dubb K, Altaf QA, Piya MK, Barnett AH, Stevens MJ. Obstructive sleep apnea and diabetic nephropathy: a cohort study. Diabetes Care. 2013:36(11):3718-25.
38. Leong WB, Nolen M, Thomas GN, Adab P, Banerjee D, Taheri S. The impact of hypoxemia on nephropathy in extremely obese patients with type 2 diabetes mellitus. J Clin Sleep Med. 2014;10(7):773-8.

39. Storgaard $H$, Mortensen $B$, Almdal $T$, Laub M, Tarnow L. At least one in three people with type 2 diabetes mellitus referred to a diabetes centre has symptomatic obstructive sleep apnoea. Diabet Med. 2014;31(11):1460-7.

40. Bulcun E, Ekici M, Ekici A, Cimen DA, Kisa U. Microalbuminuria in obstructive sleep apnea syndrome. Sleep Breath. 2015;19(4):1191-7.

41. Uyar M, Davutoglu V, Gundogdu N, Kosovali D, Sari I. Renal functions in obstructive sleep apnea patients. Sleep Breath. 2016;20(1):191-5.

42. Zhang R, Guo X, Guo L, Lu J, Zhou X, Ji L. Prevalence and associated factors of obstructive sleep apnea in hospitalized patients with type 2 diabetes in Beijing, China 2. J Diabetes. 2015;7(1):16-23.

43. Chang CP, Li TC, Hang LW, Liang SJ, Lin JJ, Chou CY, Tsai JJ, Ko PY, Chang CT. The relationships of sleep apnea, hypertension, and resistant hypertension on chronic kidney disease. Medicine (Baltimore). 2016;95(23):e3859.

44. Zhang R, Zhang P, Zhao F, Han X, Ji L. Association of Diabetic Microvascular Complications and Parameters of obstructive sleep apnea in patients with type 2 diabetes. Diabetes Technol Ther. 2016;18(7):415-20.

45. Adams RJ, Appleton SL, Vakulin A, Hanly PJ, McDonald SP, Martin SA, Lang CJ, Taylor AW, McEvoy RD, Antic NA, et al. Chronic kidney disease and sleep apnea Association of Kidney Disease with Obstructive Sleep Apnea in a population study of men. Sleep. 2017;40:1

46. Sakaguchi Y, Shoji T, Kawabata H, Niihata K, Suzuki A, Kaneko T, Okada N, Isaka Y, Rakugi H, Tsubakihara Y. High prevalence of obstructive sleep apnea and its association with renal function among nondialysis chronic kidney disease patients in Japan: a cross-sectional study. Clin J Am Soc Nephrol. 2011;6(5):995-1000.

47. Littner MR. Mild obstructive sleep apnea syndrome should not be treated. Con J Clin Sleep Med. 2007;3(3):263-4.

48. Epstein L, Kristo D, Strollo PJ Jr, Friedman N, Malhotra A, Patil SP, Ramar K, Rogers R, Schwab RJ, Weaver EM, et al. Clinical guideline for the evaluation, management and long-term care of obstructive sleep apnea in adults. J Clin Sleep Med. 2009;5(3):263-76.

49. Puckrin R, lqbal S, Zidulka A, Vasilevsky M, Barre P. Renoprotective effects of continuous positive airway pressure in chronic kidney disease patients with sleep apnea. Int Urol Nephrol. 2015:47(11):1839-45.

50. Bachmann LM, Nilsson G, Bruns DE, McQueen MJ, Lieske JC, Zakowski JJ, Miller WG. State of the art for measurement of urine albumin: comparison of routine measurement procedures to isotope dilution tandem mass spectrometry. Clin Chem. 2014;60(3):471-80.

51. Levey AS, Stevens LA, Schmid CH, Zhang YL, Castro AF 3rd, Feldman HI, Kusek JW, Eggers P, Van Lente F, Greene T, et al. A new equation to estimate glomerular filtration rate. Ann Intern Med. 2009;150(9):604-12.

52. Tanaka SI, Akanuma Y, Ohashi Y. What is the prevalence of sleep apnea syndrome in japanese patients with type II diabetes? JEDAS study. Diabetes 2009, 58.

53. Zhang R, Ji L, Zhang P. Prevalence and associated factors of obstructive sleep apnea in hospitalized patients with type 2 diabetes in China. Diabetes 2014, 63:A639.

\section{Submit your next manuscript to BioMed Central and we will help you at every step:}

- We accept pre-submission inquiries

- Our selector tool helps you to find the most relevant journal

- We provide round the clock customer support

- Convenient online submission

- Thorough peer review

- Inclusion in PubMed and all major indexing services

- Maximum visibility for your research

Submit your manuscript at www.biomedcentral.com/submit 